\title{
QUALITY OF LIFE IN WOMEN WITH LUPUS NEPHRITIS UNDERGOING RENAL TRANSPLANTATION
}

\author{
DARCI RAMOS FERNANDES (UFMA, SÃO LUIS, MA, Brasil), SUELI CARNEIRO (UERJ, RIO DE JANEIRO, RJ, \\ Brasil), ROSELINE OLIVEIRA CALISTO LIMA (UFMA, SÃO LUIS, MA, Brasil)
}

\section{BACKGROUND}

Lupus nephritis (NL) is one of the most serious manifestations of the disease, and overt nephritis is found in up to $60 \%$ of adults with systemic lupus erythematosus (SLE). End-stage renal disease (ESRD) requiring hemodialysis or renal transplantation develops in 5-22\% of patients with NL. Transplantation is a good therapeutic option for patients with ESRD due to NL, considered an important cause of morbidity and mortality, causing impacts on its quality of life. The quality of life (QOL) of chronic renal patients is influenced by the disease itself, type of renal function substitution therapy, and some factors such as age of the patient, presence of anemia, comorbidity and depression. The objective of this study was to analyze the Quality of life women with lupus nephritis undergoing kidney transplantation in a tertiary public hospital.

\section{MATERIALS AND METHODS}

Cross-sectional, observational study performed in sector of nephrology at an University Hospital in the Northeast of Brazil, with 96 renal transplant patients, in regular outpatient follow-up, of whom, 18 had a diagnosis of Lupus nephritis as a cause of terminal chronic kidney disease, a functioning graft for more than 6 months, older than 18 years, in regular outpatient follow-up, within January to June 2019, using the tools World Health Quality of Life (WHOQOL-BREF) and a socioeconomic and clinic questionnaire. The data were analyzed using Data Analysis and Statistical Software (STATA ${ }^{\circledR}$ ) version 14.0 and performed with Student's t test $(p<0.05)$.

\section{RESULTS}

Age 18 to 60 years, mean 41 years; 66\% browns; from the capital 75\%; 66\% high school; $58 \%$ single; transplant time 6 months to 12 years; $60 \%$ received organ of living donor; renal transplant time 8 months to 12 years; $33 \%$ overweight; physical activity 58\%; the psychological and social relationships domain of Whoqol-bref had the highest score while the environment domain had the lowest score; $41 \%$ reported good QOL, 34\% were satisfied with her health.

\section{CONCLUSION}

Patients who performed physical exercises showed a better quality of life. The perception of QOL by the women evaluated in this study in all domains of the WHOQOL-Bref showed to be affected. Better perception of QOL occurred in the psychological domain and worse, in the environmental. These results show that the women evaluated, must be encourage the search for methods that lead to improvement in their quality of life, among which the stimulus to regular practice of physical activities and treatment adherence 